revista ANTHROPOLÓGICAS

Ano 25, 32(1): 167-198, 2021

doi.org/10.51359/2525-5223.2021.250780

\title{
Prática de Omissão de Titulação no Currículo: um estudo entre pós-graduandos e pós-graduados
}

Ricardo Cortez Lopes ${ }^{a}$

Resumo: esse artigo busca estudar o cenário trabalhista para os pós-graduandos e pós-graduados brasileiros a partir da recorrência da prática de omissão de titulação acadêmica nos curriculum vitae desse público. Essa pesquisa é de caráter quantitativo, e sua coleta de dados ocorreu a partir da disponibilização do questionário em comunidades virtuais de pós-graduandos e graduandos na rede social Facebook, e nisto foram obtidas 302 respostas. A pesquisa indicou que a prática é bem recorrente e que está mais relacionada com a ocupação atual do respondente. Foi possível também fazer uma análise das respostas de uma pergunta aberta do questionário, 'Dois mundos', Experiência/Qualificação/Habilidades, Separação academia/mundo e o Risco da trajetória, que apontaram para um ambiente hostil tanto na dimensão pública quanto na privada, o que coloca os participantes diante de uma encruzilhada.

Palavras-chave: Omissão de titulação, Pós-graduandos, Pós-graduados, Desemprego.

Pesquisas apontam que, de fato, a maior qualificação profissional influencia na média salarial. No sentido oposto, há casos em que a qualificação prejudica a empregabilidade, por uma série de fatores socialmente estabelecidos. Nesta dificuldade residem a adoção de algumas estratégias, como veremos adiantes. Um desses recursos é o da modificação de informações de titulação na apresentação do currícu-

a Coordenador de Pós-Graduação na Faculdade CMB. Doutor em Sociologia (UFRGS). Email: rshicardo@hotmail.com. 
lo. Há quem a altere para o acréscimo (o que se constitui em uma fraude), porém também há quem o altere para a supressão. Este último é o nosso objeto de investigação, junto ao público de pós-graduados e pós-graduandos - de agora em diante aglutinados na expressão 'pósgradua(n)dos'.

É importante ressaltar que não se trata, ainda, de uma prática analisada pela literatura científica, porém já é um fenômeno abordado pelo jornalismo:

"O cenário econômico ajuda a entender essa tendência de 'rebaixamento voluntário' do currículo.

A demissão de empregados com curso superior completo no Brasil cresceu 10,8\% de março de 2015 a março de 2016 - um corte de 1 milhão de pessoas.

Os dados, apurados pelo economista Fabio Bentes, da Confederação Nacional do Comércio (CNC), para a Agência Estado, mostram ainda que esse aspecto do desemprego vai na contramão das faixas de menor instrução, que têm registrado recuos no total de demissões. Assumir um cargo com currículo muito acima do necessário implica certos riscos, apontam especialistas em mercado de trabalho.

O primeiro é a dúvida - muitas vezes legítima - da empresa sobre o porquê da candidatura, e a suspeita de que o profissional deixará o emprego tão logo consiga algo melhor.

O segundo é o receio de que o funcionário se desmotive rapidamente ou fique ansioso por uma promoção que a empresa não pode oferecer" (BBC 2017:s/p).

$\mathrm{Na}$ referida reportagem, podemos perceber uma mudança de mercado, que afeta definitivamente os empregos de nível superior. $\bigcirc$ fenômeno delimitado foi definido pela reportagem como 'rebaixamento voluntário do currículo'. O texto no caso, explicitou alguns depoimentos de atores e apresentou dados econômicos relevantes, e desta abordagem é possível projetar-se uma perspectiva da sociologia do conhecimento.

Outra reportagem reforça essa percepção jornalística:

"Não é de hoje que a qualificação se tornou um fator decisivo na hora de conseguir uma vaga no mercado de trabalho, do chão de fábrica ao alto escalão das empresas. Contudo, em tempos de crise 
econômica e desemprego em alta, existem profissionais relatando que ter um currículo muito qualificado tem dificultado o retorno ao mercado após uma demissão, por exemplo" (Junges 2017).

Essa outra notícia, da mesma época, reafirma a existência do fenômeno, porém ressaltando a crise econômica como possível fator explicativo. Ou seja, há um começo de problematização sociológica, porém, novamente, sem a abordagem explicativa característica das ciências sociais. É de se ressaltar ambas são mídias do ano de 2017, porém o fenômeno segue atual - como os dados dessa pesquisa demonstram - e ela aponta um problema social: a tendência de desemprego entre indivíduos muito qualificados. A lógica indicaria que, de acordo com a escolarização em uma economia competitiva, pessoas com menor instrução é que sofreriam com desemprego ou com subemprego, mas, na prática, o quadro parece muito mais complexo. Cabe a nós produzir um problema sociológico, como postularia Patrick Champagne, e entender que significados sociais e os acordos que estão implicados na arquitetura desse fenômeno.

Dessa maneira, o problema de pesquisa pode ser definido como: 'quais são as tendências mais gerais das ações de ocultação de qualificações entre pós-gradua(n)dos brasileiros?'. Isso postulado, buscamos o maior número possível de participantes e também uma leitura mais aprofundada do fenômeno na construção do grupo, que partilha uma série de conhecimentos. A nossa hipótese é a de que a prática vai variar de acordo com o número de indivíduos que moram junto com o praticante, o que o empurra a adotar a estratégia com mais frequência.

\section{Metodologia do estudo}

Este estudo é de caráter quantitativo e funcionou da seguinte maneira: 1) foi procedida a revisão bibliográfica (dos conceitos de currículo e empregabilidade, relacionando-os), 2) em seguida foi elaborado o instrumento de coleta, 3) foi procedida a coleta em redes sociais, em grupos na plataforma Facebook e 4) foi realizado o tratamento dos dados, levando em conta as contribuições da revisão bibliográfica. 
O questionário contou com 13 perguntas fechadas e uma aberta. O total de participantes desse estudo foi de 302 respondentes, dos quais 115 colaboraram com alguma resposta por escrito (o que dá uma taxa de 38,07\%).

Quanto às respostas quantitativas, vamos proceder as análises univariadas, bivariadas e um teste de chi quadrado de Pearson para entender o que influencia na variável denominada como 'Você chegou a alterar o seu currículo lattes para corresponder ao modificado?. Esta foi a maneira encontrada de testar a hipótese de que a omissão se referia a quantidade de moradores na casa do pós-gradua(n)do. É nessa correlação que vai ser possível encontrar o motivo da prática, fazendo um cálculo que permita explorar uma resposta possível para o fenômeno.

O que viria a ser o teste de Pearson?

"Nesse teste, as frequências observadas empiricamente são comparadas com as frequências esperadas na ocorrência da hipótese nula. $\mathrm{O}$ cálculo das frequências esperadas pode ser feito da seguinte maneira: Total da linha correspondente $\mathrm{x}$ Total da coluna correspondente

Frequência de cada campo = Tamanho da amostra" (Gil 2019:169).

Esse teste foi aplicado nas variáveis de relação concorrente com o fato da omissão. Por exemplo, a pergunta se o participante posteriormente altera o lattes para corresponder ao CV não foi testada.

Já o material escrito foi analisado de acordo com uma listagem de itens, levantando relatos factuais, sem os correlacionar entre si diretamente. No entanto, eles foram unidos em grupos de significação para, por fim, poderem ser cruzados com os dados quantitativos e ajudar na resolução do problema de pesquisa.

\section{Referencial teórico: currículo e empregabilidade}

O conceito de currículo vitae é essencial para esse estudo, uma vez que sua construção é a prática social que oportuniza a ação da 170 
omissão. O currículo é uma palavra de origem muito antiga, do latim, como se pode presumir pela seguinte pesquisa:

"O termo currículo deriva da palavra latina curriculum (cuja raiz é a mesma de cursus e currere). Na Roma Antiga falava-se do cursus honorum, a soma das honras que o cidadão ia acumulando à medida que desempenhava sucessivos cargos eletivos e judiciais, desde o posto de vereador ao cargo de cônsul. $O$ termo era utilizado para significar carreira, e, por extensão, determinava a ordenação e a representação de seu percurso. Esse conceito, em nosso idioma, bifurca-se e assume dois sentidos: por um lado, refere-se ao percurso ou decorrer da vida profissional e a seus êxitos (ou seja, é aquilo a que denominamos de curriculum vitae, expressão utilizada pela primeira vez por Cícero)" (Sacristán 2013:16).

Existencialmente, o currículo é, literalmente, o percurso da vida de alguém, filtrando seus êxitos e ocultando seus percalços. Portanto, o currículo é uma arma para sedução, pois ele exclui as vicissitudes e constrói uma caixa preta, em um ser humano livre de falhas, ao menos do ponto de vista profissional. Assim,

“'Curriculum vitae' significa 'curso da vida'. Tratando-se de um 'curriculum vitae' dum profissional [...], é óbvio que corresponderá ao curso da sua vida profissional; por outras palavras, àquilo que ele fez, desse ponto de vista, até ao momento em que o está a escrever. Aceite a definição, é evidente que nele não caberão descrições mais ou menos pormenorizadas do ou dos Serviços onde o autor do 'curriculum' trabalhou, a não ser que esse ou esses Serviços tenham sentido alterações, melhoramentos, incrementos, da sua responsabilidade pessoal, para além do seu mero trabalho diário e rotineiro. Essas alterações, esses progressos, por si introduzidos, ou estimulados, sim, farão com certeza parte do seu 'curriculum vitae'; o resto, não. Além disso, poderá ser lícito em termos curriculares realçar que teve oportunidade de trabalhar num local e com profissionais que façam de algum modo uma diferença significativa em relação ao comum dos centros da sua área [...] O 'Curriculum vitae' deve ser exclusivamente a descrição do que o seu autor produziu enquanto profissional, daquilo que mostrou ser capaz de fazer na fase pré-profissional, e ainda, eventualmente, de actividades [...] que traduzem conhecimentos [...], interesse e capacidade de ensinar, de organizar, de criar, de inovar, de fazer (Almeida 2017:52). 
O currículo é uma descrição da atuação positiva na área e substitui a palavra do próprio candidato a um emprego. No mundo do trabalho, atualmente, o currículo precisa ser resumido, ele não pode ser a descrição completa da trajetória profissional, por conta do volume de candidatos:

"Para um candidato em início de carreira, uma página é suficiente para o CV. No caso de profissionais mais experientes, o limite pode ser de duas a três páginas, na opinião de Paulo Dias, da Mariaca. 'Currículos muito longos e prolixos dificultam a localização de informações importantes', explica” (Gasparini 2014:s/p).

Ou seja, o currículo, mais do que uma trajetória individual, é um resumo tendencioso, e precisa se adaptar para a vaga e também à alta demanda de currículos recebidos por recrutadores - nesse caso, um volume grande de informações, embora demonstre as conquistas do dono do currículo, inviabiliza uma visão mais panorâmica voltada para os pré-requisitos. Ou seja, um currículo é uma construção dinâmica, por um lado ele sofre adições paralelas com a trajetória, por outro lado ele precisa se adaptar para as situações onde será apresentado, pois muitas vagas são criadas pelas empresas e exigem foco em habilidades bem específicas, o que permite vários diplomas possíveis para o mesmo cargo (Lopes 2020).

\section{Ampliação da oferta de pós-graduações}

O objetivo desta seção é aproximar os fenômenos de ampliação das vagas de pós-graduação de trabalho e as dificuldades de inserção no mercado. Se há a aproximação desses dois fenômenos, isso justificaria alterações no currículo na omissão de informações.

Muitos estudos apontam para uma série de dificuldades para pósgraduandos no contexto brasileiro. Desde questões mais existenciais, adoecimento mental e também dificuldades econômicas. Os estudos se focam nos indivíduos, porém também é possível abordar-se a questão da expansão não correspondida do sistema de ensino. 
Desde a LDB, de 1996, o sistema educacional tem se expandido, o que inclui o sistema de pós-graduação, o qual faz parte do nível superior. A pós-graduação, no Brasil, está organizada por meio dos programas:

"O sistema de pós-graduação brasileiro funciona por meio de programas e agências de fomento. Esses programas e agências possuem autonomia para definir suas regras, o que os faz ser um guia à legalidade das ações dos alunos e um parâmetro a ser levado em conta na tomada de suas decisões [...] Atualmente, os títulos de Mestrado e Doutorado são concedidos por meio de programas de pós-graduação. A graduação em nível de especialização lato sensu é muito mais antiga, e remete a 1925 [...] Os programas foram se estabelecendo e se sobrepondo a outros modelos prévios e pontuais de atribuição de títulos, de modo que também foram aderindo paulatinamente à questão da pesquisa, que começa a ser o carro chefe de sua expansão [...]. Dessa ênfase é que nascem os planos nacionais de pós-graduação, esses também sucessivos. Atualmente, os programas possuem autonomia para tratar com os bolsistas e distribuir as verbas a eles destinadas" (Lopes, Bandeira \& Franz 2020:6).

Portanto, o modelo de programas se impôs sobre todos os outros e passou a financiar a pesquisa na maioria dos casos, provindo o dinheiro das agências. A existência dessa estrutura, no entanto, não implica necessariamente na extensão, de modo que foi uma delas que capitaneou essa ampliação, tal qual no modelo norte-americano (Zotesso 2021):

"Esta agência, fundada nos anos de 1950 com o objetivo de capacitação do pessoal de ensino superior, após se constituir, por décadas, em um órgão do Estado para financiamento e avaliação da pós-graduação, acentuou, a partir de 1997, sua função reguladora com o objetivo de organizar e reorganizar não somente os programas, mediante seu modelo de avaliação, mas todo o sistema, tornando-se, assim, uma efetiva 'agência reguladora da pós-graduação brasileira'. Este fato, segundo a CAPES, justificava-se pela necessidade de formação de pesquisadores e da criação de um sistema de pós-graduação mais produtivo, regulado e flexível, para orientar e reorientar suas pesquisas e a produção de conhecimento [...] expansão do número de matrículas entre graduação $(77,4 \%)$ e pós-graduação $(155,1 \%)$ (Silva Júnior, Ferreira \& Kato 2013:443). 
Podemos observar que houve um investimento massivo de recursos nos governos para o financiamento dos programas. A explicação dessa expansão mais abrupta pode ser encontrada na ciência política, no paradigma da social-democracia, que é a que guia o Partido dos Trabalhadores e, por consequência, dos governos Lula e Dilma (Bresser-Pereira 2013), onde a massificação iniciou e também acabou. Esse tipo de política de governo buscou o bem-estar social, focando na resolução das questões sociais partindo do estado - entre essas questões estaria o acesso a educação. Assim, o investimento financeiro nesse setor foi muito grande e isso se refletiu em concursos públicos, financiamentos em instituições particulares e concessões de bolsa - as bolsas permitindo a dedicação para concorrer a esses cargos. No entanto, por motivos que ainda precisam ser estudados com maior quantidade de dados, o estado retirou-se como indutor do desenvolvimento e a dinâmica mudou. Ao menos o setor público passou a não ser mais um polo tão receptivo. E quanto ao setor privado?

"A alta competitividade do mercado de trabalho contemporâneo e a precarização de muitos vínculos de trabalho têm afetado os jovens diplomados brasileiros. O diploma universitário parece já não garantir tantas vantagens no que se refere à busca por um emprego. Pimentel (2007) problematiza o fato de o número de empregos ser desproporcional ao número de recém-formados à procura de uma colocação profissional. Mattos (2011), por exemplo, constatou que, diante de um estreitamento percebido de oportunidades de trabalho, o alongamento da escolarização torna-se uma possível escolha entre os jovens que estão prestes a finalizar seus cursos de graduação. De acordo com Pimentel (2007), para muitos jovens, poder dizer que estão estudando suaviza o impacto negativo de dizer que estão fora do mercado de trabalho (Silva \& Bardagi 2015:685).

Ou seja, a expansão desse sistema se deu por via estatal e continuou sendo financiado por ele. No entanto, a retração abrupta de investimentos ocasionou que as ofertas de posições e bolsas se perdessem, o que criou um residual que precisou ir em busca de outras ocupações. Esse residual, no entanto, não encontrou um mercado aberto. No ano de 2017 essa situação já estava escancarada, porém 
não é difícil inferir que ela perdurou com governos que não são de orientação social-democrata e nem com a crise econômica provocada pela pandemia. Ademais, a economia brasileira não tem um lastro histórico de se apoiar no ensino formal:

"Para entender melhor esses dados, a Pesquisa Nacional por Amostra de Domicílios Contínua (Pnad Contínua) (2019) revelou que entre os 47,3 milhões de pessoas de 15 a 29 anos, $23 \%$ não estudam e nem trabalham. No segundo trimestre de 2018, a taxa de desemprego no grupo de 18 a 24 anos estava em 26,6\% - mais que o dobro da média geral do país no mesmo período $(12,4 \%)$. Quanto ao nível de escolaridade o Censo 2010 assinala que apenas 16,2\% dos jovens de todo o país chegaram ao ensino superior, $46,3 \%$ apenas concluíram o ensino médio e 35,9\% têm sua escolaridade limitada ao ensino fundamental" (Gomes, De Oliveira \& Andrade 2019:25).

Assim, podemos perceber que, paralelo ao crescimento dos programas há uma retração de empregabilidade de pessoas diplomadas exatamente no mesmo período, o que não foi retomado posteriormente. Levando em conta que muitos dos cursos e disciplinas são exportados de outros espaços - lembremos que a universidade brasileira, por exemplo, baseou-se em modelos como o humboldtiano, de origem prussiana - é possível se afirmar que o estado estava buscando induzir o progresso por meio dos cursos, que possibilitariam a expansão do mercado. Porém, o mercado aparentemente encontrou um teto e depois retraiu, o que criou o descompasso. Isso se refletiu num mercado mais acirrado:

"Esta insegurança dos alunos em final de curso frente ao início da atividade profissional faz com que os alunos refiram a necessidade de auxílio à inserção no mercado de trabalho, e sintam-se especialmente interessados em ferramentas instrumentalizadoras, como estratégias de busca de emprego, oficinas de currículo etc." (Bardagi et al 2006:71).

Essa insegurança sentida cria a necessidade de estratégias para a inserção (e reinserção) no mercado, entre elas as oficinas de currículo mencionadas no trecho. Porém, aqui estamos abordando a omissão de dados nos currículos como maneira de os tornar mais atraentes. As características dessa atração podem ser conhecidas via pesquisa social. 


\section{Análise dos dados quantitativos}

$O$ primeiro gráfico refere-se a região onde habita atualmente o respondente. Nele podemos extrair, a partir do cruzamento com outras variáveis, uma evidência das oportunidades ocupacionais para pós-gradua(n)dos daquela região em específico:

Gráfico 1: Qual a região do brasil em que você reside atualmente?

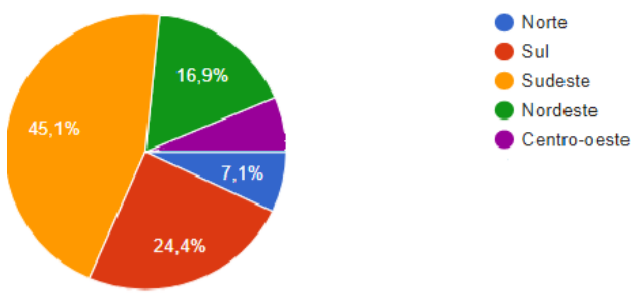

Fonte: Autoria própria.

Podemos observar uma grande preponderância de respostas da região sudeste $(45,1 \%)$, seguida da sulina $(24,4 \%)$ e da nordestina $(16,9 \%)$. Essas porcentagens, de fato, refletem a distribuição de programas ao longo do território nacional (imagem 1) de acordo com sua antiguidade, e assim a pesquisa conseguiu um pouco de amostragem representativa.

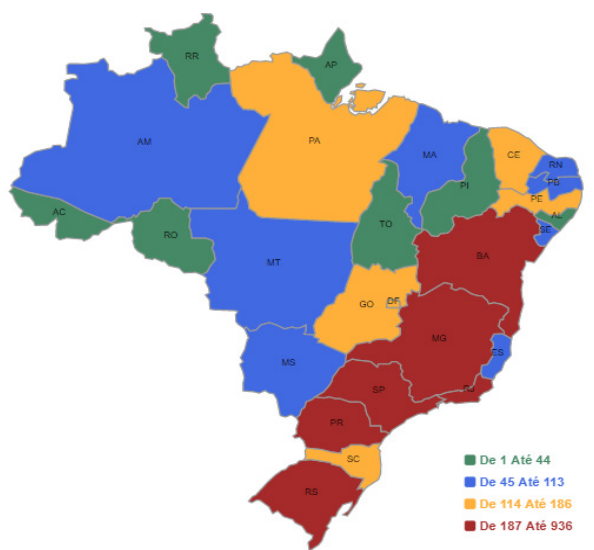

Imagem 1: Distribuição dos programas de pós-graduação no Brasil. Fonte: https://geocapes.capes.gov.br/geocapes/\# 
Com relação à idade, pudemos perceber uma concentração das respostas em duas regiões do gráfico, conforme o gráfico 2:

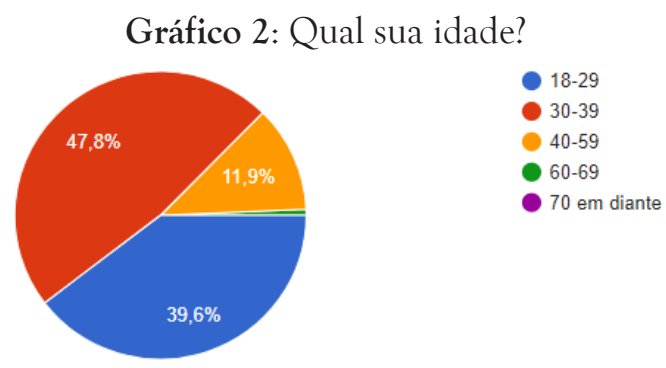

Fonte: Autoria própria.

Quase metade dos respondentes $(47,8 \%)$ está na faixa dos 30 anos, enquanto outra parte $(39,6 \%)$ está na faixa dos 20 , seguidos de $11,9 \%$ que habitam a faixa dos 40 . Essa distribuição aponta que a maioria está na faixa economicamente ativa, o que reforça o argumento de que são pessoas que podem buscar adentrar no mercado de trabalho. Essa proporção obtida é corroborada por dados oficiais: "Em 2019, aproximadamente $45 \%$ dos alunos que frequentam um curso de especialização de nível superior têm idade entre 25 a 34 anos" (Agência Brasil 2019:s/p). Ou seja, a amostra difere pouco do censo, apenas em 2 pontos, mesmo que a escala tenha mudado um pouco.

Já o gráfico 3 refere-se ao modo de vida dos participantes:

Gráfico 3: Qual sua principal ocupação atual?

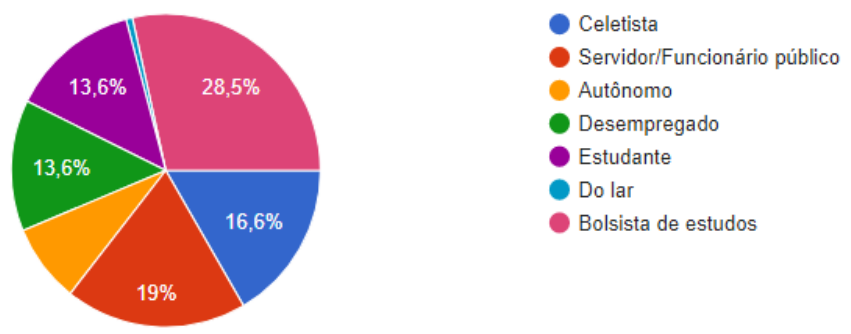

Fonte: Autoria própria. 
A maioria dos respondentes (28,5\%) declarou-se como bolsista, seguidos dos funcionários/servidores públicos (19\%) e dos celetistas $(16,6 \%)$ e dos desempregados e estudantes sem bolsa (13,6\% cada). Essa distribuição se apresentou bastante uniforme, pois nenhuma das categorias despontou decisivamente em relação às outras. Podemos perceber, adicionalmente, que a maioria dos pós-gradua(n)dos participantes vive de bolsa, mas o restante está em outras ocupações. Falta saber, agora, da área de atuação, exposto no gráfico 4:

Gráfico 4: Você exerce profissão relacionada com a sua área de formação?

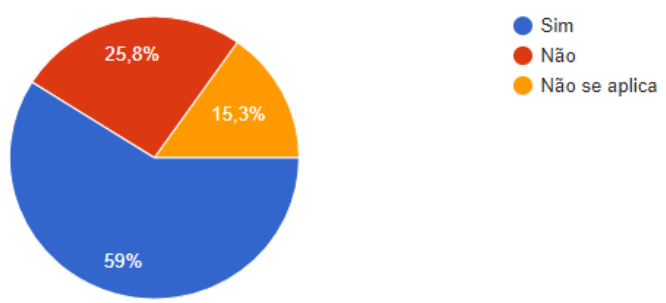

Fonte: Autoria própria.

A grande maioria (59\%) dos atuantes consegue se dedicar à área de formação, porém parte significante não o logra, pois atua em outro segmento (25,8\%). Esse dado indica que parte significativa dos participantes não atua em sua área, o que indica que a sub-remuneração é apenas um dos problemas, ainda há quem estuda e não consegue se inserir em sua própria área de formação. A depender da área, é um privilégio trabalhar-se com a própria especialidade.

O gráfico 5 abordou a relação de gêneros:

Gráfico 5: Qual seu gênero?

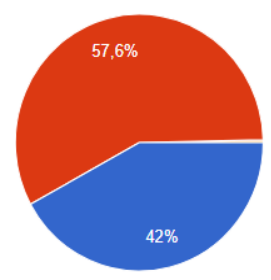

Masculino

Fonte: Autoria própria. 
Podemos observar que a maioria das respostas foi provida por mulheres cis ou trans $(57,6 \%)$, restando $42 \%$ de respostas para homens cis ou trans. Essas proporções refletem também as dos levantamentos oficiais, que resultaram nos números de $54,5 \%$ de mulheres e $45,5 \%$ de homens matriculados no ano de 2019 (Righetti \& Gamba 2021). Assim, há uma diferença de 3 pontos em cada uma delas, o que não é estatisticamente relevante e comprova certa representatividade de nossa coleta, embora essa não tenha sido a intenção inicial.

A próxima variável, exposta no gráfico 6 , remonta à hipótese de estudo, que foi relacionando a prática ao número de companheiros de habitação:

Gráfico 6: Você mora com quantas pessoas?

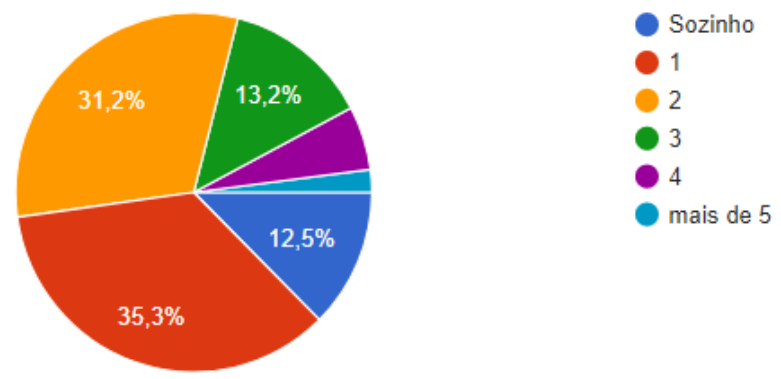

Fonte: Autoria própria.

Podemos observar que a maioria $(35,3 \%)$ mora com uma pessoa ou duas $(31,2 \%)$, seguidos de quem mora com três $(13,2 \%)$ ou mais de $5(12,5 \%)$. Se os números estivessem mais concentrados nessas duas últimas categorias, poderíamos afirmar que se trata de repúblicas estudantis o fato de haver a aglomeração. No entanto, a distribuição das ocorrências aponta para um estudante que não se 'afasta do mundo' para dedicar-se aos estudos: ele está inserido nas dinâmicas sociais junto a diversos atores e precisa lidar com dilemas semelhantes aos de quem já está no mercado de trabalho, como por exemplo a vida com um cônjuge ou com algum filho(a). Ou seja, a bolsa não parece estar ga- 
rantindo a segurança e esse pesquisador está dando continuidade à sua vida sem um momento de reclusão e investimento em publicações.

O gráfico 7 permite refletir sobre o perfil dos respondentes:

Gráfico 7: Qual sua escolaridade?

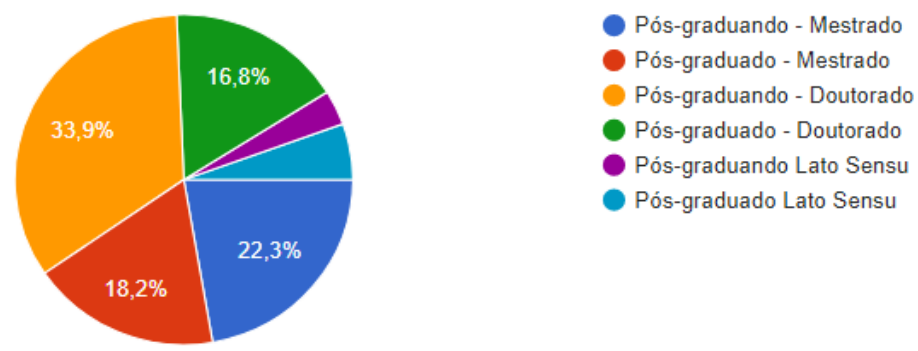

Fonte: Autoria própria.

Podemos observar que os doutorandos são a maioria dos respondentes $(33,9 \%)$, seguidos dos mestrandos $(22,3 \%)$, dos mestres $(18,2 \%)$ e dos doutores (16,8\%). Essa proporção aponta para uma transição: a maioria dos participantes demonstra que há uma preocupação com a empregabilidade desde o momento de formação, o que aponta para um desprestígio da bolsa em si, ou da percepção de sua finitude. Será que isso se reflete nas diferentes áreas? A resposta pode estar parcialmente no gráfico 8:

Gráfico 8: Qual a área em que você se formou para atuar?

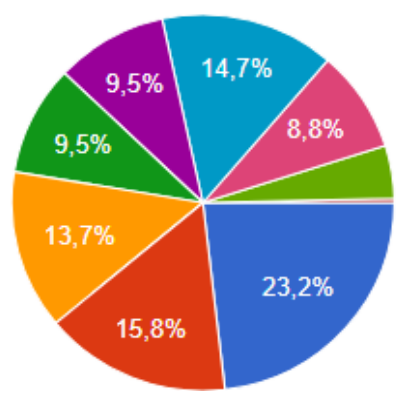

Ciências Humanas

Ciências Sociais Aplicadas

Ciências Exatas e da Terra

Engenharias

Linguística, Letras e Artes

Ciências Biológicas

Ciências da Saúde

- Ciências Agrárias

- Não desejo informar

Fonte: Autoria própria. 
A maioria dos respondentes, portanto, pertence às ciências humanas $(23,2 \%)$, seguidos das ciências sociais aplicadas $(15,8 \%)$, das biológicas $(14,7 \%)$, das exatas e da terra $(13,7 \%)$. Não conseguimos encontrar, no entanto, um dado com relação a matriculado sem pós-graduação nestas áreas, então não conseguimos contrastar os números.

No gráfico 9 encontramos a variável principal do estudo aplicada a terceiros, com o objetivo de gerar evidências sobre a amplitude do fenômeno:

Gráfico 9: Você conhece alguém que já retirou informações de títulos de seu currículo na hora de apresentá-lo em algum processo seletivo relacionado a trabalho?

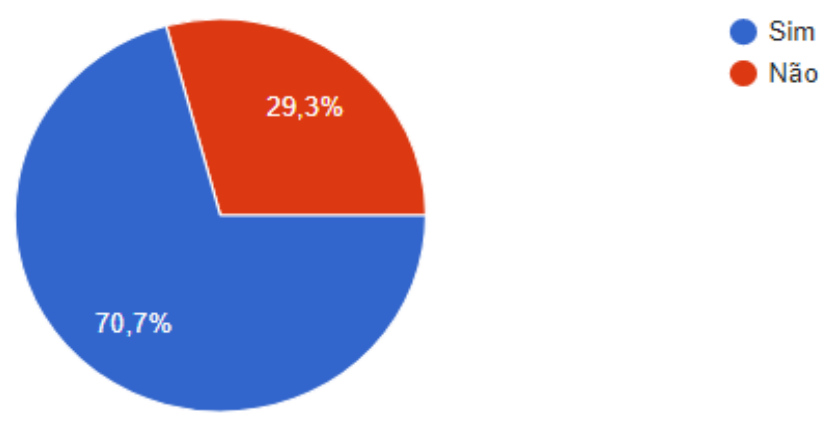

Fonte: Autoria própria.

Podemos observar que a maioria dos respondentes $(70,7 \%)$ observou o fenômeno diretamente acontecendo, enquanto 29,3\% afirmaram que não o viram. É claro que esse dado não é definitivo, porém se formos multiplicar por dois cada um desses que viram (supondo que conhecem uma pessoa que omitiu), teríamos um número de [calcular]. Assim, o fenômeno pode se tornar alarmante se esse número for em uma escala maior (e provavelmente o é).

O gráfico 10 foca-se na variável principal do estudo: 
Gráfico 10: Você já retirou informações de títulos de seu currículo na hora de apresentá-lo em algum processo seletivo relacionado a trabalho?

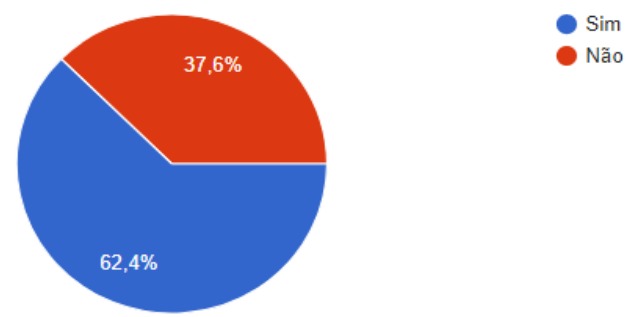

Fonte: Autoria própria.

Podemos observar um decréscimo nas proporções de 'sim' (62,4\%) e 'não' $(37,6 \%)$ em relação à pergunta anterior. Ainda, a maioria se mantém a mesma, e os respondentes afirmam que já omitiram seus títulos em seleções profissionais em pelo menos um momento. Cumpre notar que essa proporção variou muito ao longo do tempo de coleta, e a resposta 'não' chegou a ser majoritária por diversos momentos. Isso é um indicativo de que o estudo pode ter sido mais compartilhado na medida em que o fenômeno foi se mostrando existente.

Posteriormente, perguntamos o motivo dessa alteração curricular (gráfico 11), e as porcentagens obtidas foram as seguintes:

Gráfico 11: Por qual motivo você retirou informações de títulos de seu currículo na hora de apresentá-lo em algum processo seletivo relacionado a trabalho?

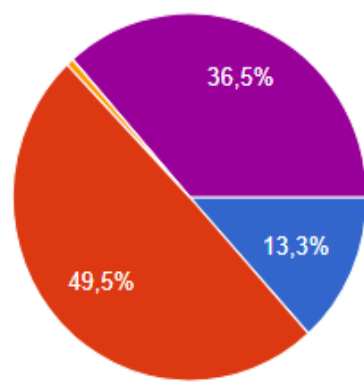

Não achei relevante para um cargo em questão de acordo com a descrição desse cargo

Medo de ser muito qualificado para um cargo pretendido

- Não acha relevante essa informação num geral

Má reputação da instituição onde estudou

- Não se aplica

Fonte: Autoria própria. 
É claro que essa pergunta seria muito mais adequada se fosse formulada de maneira aberta, porém optamos pela 'principal' motivação como uma maneira de não excluir as demais, além de deixarmos a possibilidade de o participante registrar uma resposta aberta. Quase metade das respostas (49,5\%) afirmaram que temiam uma super qualificação, enquanto uma proporção menor (36,5\%) não considerou a informação relevante para a seleção em questão. Porcentagens muito pequenas consideraram os títulos não relevantes para o currículo vitae no geral ou sua instituição como não relevante. Essas porcentagens indicam que é possível aferir que o título é importante a nível de realização pessoal do titulado, porém ele não o considera alinhado com a profissão para a qual ela qualifica.

O penúltimo dado está expresso no gráfico 12 e relaciona-se com a 'manutenção' da 'farsa':

Gráfico 12: Você chegou a alterar o seu currículo lattes para corresponder ao modificado?

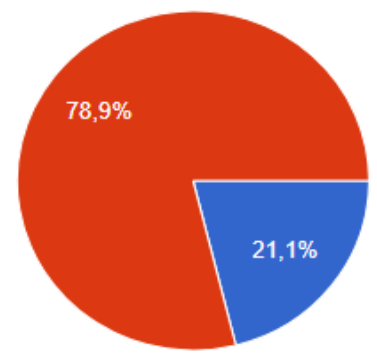

Fonte: Autoria própria.

Podemos observar que esses dados reforçam a separação entre mundo do trabalho e academia em ao menos um sentido, o que foi bastante discutido nas respostas às perguntas abertas. As respostas negativas somaram $78,9 \%$ do total, o que indica que os pós-gradua(n) dos não consideram que os empregadores saibam o que é a plataforma lattes ou que não estariam dispostos a bater as informações entre os currículos. 
Por fim, o último gráfico, o 13, expressa-se da seguinte maneira:

Gráfico 13: Qual foi sua principal motivação para seguir obtendo títulos acadêmicos?
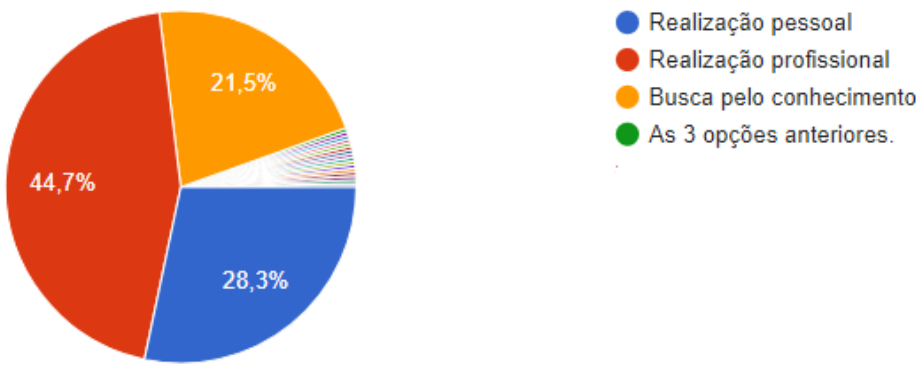

Fonte: Autoria própria.

Podemos observar, portanto, que a maioria dos respondentes $(44,7 \%)$ cursaram pós por realização profissional, ou seja, seu foco estava diretamente na profissão. Nesse ponto, podemos teorizar que há um sentimento de frustração maior nesse público com relação aos outros - o que foi corroborado nas respostas abertas - pois estes últimos ingressaram nos programas por realização pessoal $(28,3 \%)$ ou pelo conhecimento em si $(21,5 \%)$ ou todas as opções anteriores $(5,5 \%)$ - destinada para quem não conseguiu escolher uma principal. Nesse caso, esse desencontro pode ser fatal para a continuidade dos programas de pós-graduação no país, pois uma esperança de um feedback positivo do mercado - ou uma vaga no serviço público - parece ser o que moveu inicialmente os candidatos.

A seguir apresentaremos os cruzamentos entre essas variáveis. No entanto, tal relação foi parametrizada com base na variável da omissão ou não dos títulos, partindo daí os cruzamentos para, posteriormente, se determinar as variáveis que a afetam, o que foi feito através de um teste de chi quadrado de Pearson. O primeiro cruzamento ocorreu na tabela 1 : 
Tabela 1: Região e omissão

\begin{tabular}{|c|c|c|c|c|c|c|}
\hline & Centro-oeste & Nordeste & Norte & Sudeste & Sul & Total geral \\
\hline Não & $3,45 \%$ & $5,52 \%$ & $2,07 \%$ & $17,24 \%$ & $9,66 \%$ & $37,93 \%$ \\
\hline Sim & $3,10 \%$ & $11,38 \%$ & $5,17 \%$ & $27,93 \%$ & $14,48 \%$ & $62,07 \%$ \\
\hline Total geral & $6,55 \%$ & $16,90 \%$ & $7,24 \%$ & $45,17 \%$ & $24,14 \%$ & $100,00 \%$ \\
\hline
\end{tabular}

Podemos ob servar que os que mais omitem são os pós-gradua(n) dos do sudeste $(27,93 \%)$, enquanto os que menos omitem são os do Centro-oeste $(3,10 \%)$. Os valores intermediários são bem distantes dos valores do sudeste, o que é uma evidência de que essa região é a que possui menor número de colocações profissionais em relação ao número de formados. Essa região, também, apresentou o maior números de respondentes com 'não', o que indica que há um grande mercado que inclui, porém também exclui os títulos. A região Norte foi a que menos respondeu 'não' (2,07\%), enquanto a região centro -oeste foi a que teve mais próxima as respostas 'sim' e 'não' $(3,45 \%)$, o que indica que essa região pode ser evidência de um maior equilíbrio na aceitação dos títulos.

Podemos observar outro cruzamento quando consideramos a idade na tabela 2:

Tabela 2: idade e omissão

\begin{tabular}{|c|c|c|c|c|c|c|}
\hline & SR & $18-29$ & $30-39$ & $40-59$ & $60-69$ & Total geral \\
\hline Não & $0,34 \%$ & $15,17 \%$ & $16,55 \%$ & $5,17 \%$ & $0,69 \%$ & $37,93 \%$ \\
\hline Sim & $0,34 \%$ & $23,45 \%$ & $31,38 \%$ & $6,90 \%$ & - & $62,07 \%$ \\
\hline Total geral & $0,69 \%$ & $38,62 \%$ & $47,93 \%$ & $12,07 \%$ & $0,69 \%$ & $100,00 \%$ \\
\hline
\end{tabular}

Podemos observar que quem está na faixa dos 30 anos são os que mais responderam 'não', e também os que tiveram maior porcentagem de $\operatorname{sim}(31,38 \%)$. Outro dado interessante é que a geração 
com 60 anos parece nunca ter omitido sua formação, o que aponta para transformações históricas do campo de trabalho - e a geração até 20 anos tem um porcentual menor de distância entre respostas sim e não, 8 pontos percentuais. No entanto, na geração de 40 anos a distância é ínfima, de 1,73, o que indica que ela representou uma transição para as últimas gerações de respondentes.

Podemos observar também a ocupação na tabela 3:

Tabela 3: ocupação e omissão

\begin{tabular}{|c|c|c|c|c|c|c|c|c|}
\hline & $\begin{array}{l}0 \\
\Xi \\
0 \\
0 \\
0 \\
气 \\
\end{array}$ &  & 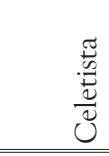 & 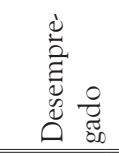 & $\frac{\bar{t}}{\circ}$ & 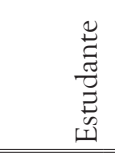 & 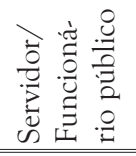 & $\begin{array}{l}\widetilde{\widetilde{J}} \\
0\end{array}$ \\
\hline Não & $4,83 \%$ & $9,66 \%$ & $6,90 \%$ & $2,41 \%$ & $0,34 \%$ & $5,17 \%$ & $8,62 \%$ & $37,93 \%$ \\
\hline Sim & $3,45 \%$ & $18,97 \%$ & $9,66 \%$ & $10,69 \%$ & $0,34 \%$ & $8,28 \%$ & $10,69 \%$ & $62,07 \%$ \\
\hline Total geral & $8,28 \%$ & $28,62 \%$ & $16,55 \%$ & $13,10 \%$ & $0,69 \%$ & $13,45 \%$ & $19,31 \%$ & $100,00 \%$ \\
\hline
\end{tabular}

Fonte: Autoria própria.

Os bolsistas foram os maiores respondentes para 'sim' (18,97\%), e também foram os maiores respondentes de 'não' (9,66\%), o que é compreensível porque também foram os maiores participantes na pesquisa. Quem respondeu menos 'sim' e 'não' foram os donos de casa $(0,34 \%)$. Um resultado muito interessante de se analisar foram os dos autônomos, que obtiveram porcentagens semelhantes de resposta 'sim' $(3,45 \%)$ e 'não' $(4,83 \%)$, pois isso indica que os autônomos (que a princípio não precisariam se submeter a seleções profissionais) também omitem títulos, o que dá uma ideia de uma representação sobre esses títulos. O instigante é que os desempregados e servidores/ funcionários públicos omitiram na mesma medida (10,69\%), o que indica que a prática é recorrente em diferentes ocupações, não é privilégio de celetistas $(9,66 \%)$ e de estudantes $(8,28 \%)$.

Outra dado relevante é a de gênero e omissão, na tabela 4 : 
Tabela 4: gênero e omissão

\begin{tabular}{lrrrr} 
& Feminino & Masculino & Não binário & Total geral \\
\hline \hline Não & $23,45 \%$ & $14,48 \%$ & - & $37,93 \%$ \\
Sim & $33,79 \%$ & $27,93 \%$ & $0,34 \%$ & $62,07 \%$ \\
Total geral & $57,24 \%$ & $42,41 \%$ & $0,34 \%$ & $100,00 \%$
\end{tabular}

Podemos observar que as mulheres tendem a omitir mais $(33,79 \%)$ na comparação com os homens $(27,93 \%)$. É claro que isso pode ocorrer porque, justamente, há mais mulheres cursando pós-graduação, porém a comparação com quem diz 'não' promove uma reflexão interessante: a distância que separar os sim e o não das mulheres é praticamente de 10 pontos percentuais, enquanto para os homens é de aproximadamente 13 pontos, o que indica que há mais variedade de resposta dos homens ao mercado do que das mulheres - dado que abre espaço para uma pesquisa qualitativa. Outro ponto interessante é que os gêneros não-binários apareceram omitindo títulos, o que confirma algumas estatísticas de que sua empregabilidade é prejudicada no mercado de trabalho brasileiro.

Como já referimos anteriormente, a quantidade de indivíduos na moradia era nossa hipótese de estudo e está expressa a relação na tabela 5:

Tabela 5: com quantos mora e omissão

\begin{tabular}{|c|c|c|c|c|c|c|c|}
\hline & 1 & 2 & 3 & 4 & mais de 5 & Sozinho & Total geral \\
\hline Não & $12,76 \%$ & $11,72 \%$ & $4,83 \%$ & $2,41 \%$ & $0,34 \%$ & $5,86 \%$ & $37,93 \%$ \\
\hline Sim & $22,07 \%$ & $20,00 \%$ & $7,93 \%$ & $3,45 \%$ & $1,72 \%$ & $6,90 \%$ & $62,07 \%$ \\
\hline Total geral & $34,83 \%$ & $31,72 \%$ & $\begin{array}{c}12,76 \% \\
\text { Fonte: }\end{array}$ & $\begin{array}{r}5,86 \% \\
\text { oria próp }\end{array}$ & $2,07 \%$ & $12,76 \%$ & $100,00 \%$ \\
\hline
\end{tabular}

Podemos observar que quem mais omite o currículo são aqueles que moram com uma pessoa $(22,07 \%)$, e os que menos omitem são 
os que vivem com mais de 5 (1,72\%). Esse dado pode indicar que os pós-graduandos não necessariamente sejam responsáveis pelos lares onde habitam, ou se o são não utilizam sua formação como um instrumento para a sua situação trabalhista. Assim, a hipótese já poderia ser descartada antes do teste de Pearson, porém o mesmo teste permitiu encontrar qual a verdadeira relação.

É possível também verificar a escolaridade e a omissão na tabela 6:

Tabela 6: escolaridade e omissão

\begin{tabular}{|c|c|c|c|c|c|c|c|c|}
\hline & 点 & 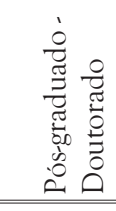 & 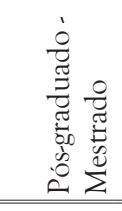 & 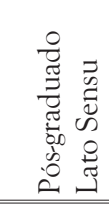 & 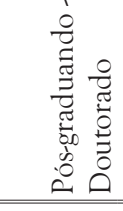 & 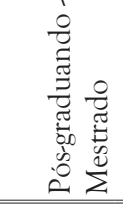 & 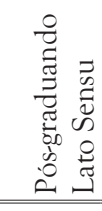 & $\stackrel{\frac{\pi}{0}}{0}$ \\
\hline Não & $1,03 \%$ & $7,59 \%$ & $7,59 \%$ & $1,03 \%$ & $12,07 \%$ & $6,90 \%$ & $1,72 \%$ & $37,93 \%$ \\
\hline Sim & - & $8,97 \%$ & $10,34 \%$ & $4,48 \%$ & $21,72 \%$ & $14,83 \%$ & $1,72 \%$ & $62,07 \%$ \\
\hline Total geral & $1,03 \%$ & $16,55 \%$ & $17,93 \%$ & $5,52 \%$ & $33,79 \%$ & $21,72 \%$ & $3,45 \%$ & $100,00 \%$ \\
\hline
\end{tabular}

Podemos observar que quem mais omitiu foram os doutorandos $(21,72 \%)$, quase o dobro dos mestrandos $(14,83 \%)$ e mestres (10,34\%). O mestrado, assim, aparece como um 'rito de passagem': ele evidencia o cenário para o pós-graduando, que passa a buscar outras colocações depois de sua matrícula. Essa é uma forte evidência de que a educação da graduação não levou em consideração a questão mercadológica, o que acaba se refletindo na pós-graduação stricto sensu - o que parece não ocorrer na graduação lato sensu, que obteve respostas de 4,48 (para formados) e 1,72\% para os matriculados.

Outra questão relevante são as áreas que omitem, expressa na tabela 7: 
Tabela 7: área e omissão

\begin{tabular}{|c|c|c|c|c|c|c|c|c|c|c|}
\hline & 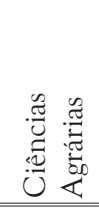 & 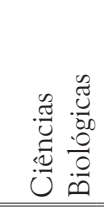 & 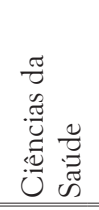 & 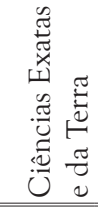 & 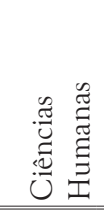 & 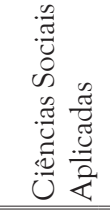 & 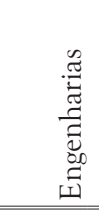 & 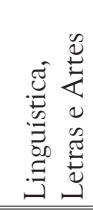 & $\frac{a}{\infty}$ & 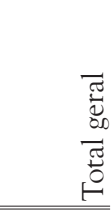 \\
\hline Não & $1,72 \%$ & $4,48 \%$ & $2,07 \%$ & $5,86 \%$ & $8,28 \%$ & $5,17 \%$ & $3,79 \%$ & $3,79 \%$ & $2,75 \%$ & $37,93 \%$ \\
\hline Sim & $2,76 \%$ & $9,31 \%$ & $6,55 \%$ & $7,24 \%$ & $14,14 \%$ & $10,34 \%$ & $5,52 \%$ & $5,17 \%$ & $1,03 \%$ & $62,07 \%$ \\
\hline $\begin{array}{l}\text { Total } \\
\text { geral }\end{array}$ & $4,48 \%$ & $13,79 \%$ & $8,62 \%$ & $\begin{array}{l}13,10 \% \\
\text { Fonte: }\end{array}$ & $22,41 \%$ & $15,52 \%$ & $9,31 \%$ & $8,97 \%$ & $3,79 \%$ & $100,00 \%$ \\
\hline
\end{tabular}

Podemos observar que os maiores omissores foram os cientistas humanos $(14,14 \%)$, seguidos dos cientistas sociais aplicados $(10,34 \%)$, seguidos dos cientistas biológicos $(9,31 \%)$. Os que menos omitiram foram os cientistas agrários (2,76\%). Esses dados indicam que, dentro do caso estudado, os cientistas humanos possuem os diplomas menos valorizados, o que se reflete nas ciências sociais aplicadas. Possivelmente, a mesma lógica se aplica para as ciências biológicas, cujas muitas das práticas exigem um laboratório, algo difícil de custear fora da dimensão pública (especialmente no Brasil, como demonstraram algumas falas).

Outro dado, o da tabela 8, é sobre o quanto alguém que omitiu titulação conhece quem o fez:

Tabela 8: conhece alguém e omissão

\begin{tabular}{lrrrr} 
& SR & Não & Sim & Total geral \\
\hline \hline Não & & $23,10 \%$ & $14,83 \%$ & $37,93 \%$ \\
Sim & $0,34 \%$ & $6,21 \%$ & $55,52 \%$ & $62,07 \%$ \\
Total geral & $0,34 \%$ & \begin{tabular}{c}
$29,31 \%$ \\
\multicolumn{3}{c}{ Fonte: Autoria própria. }
\end{tabular} & 70,34\% & $\mathbf{1 0 0 , 0 0 \%}$ \\
& \multicolumn{4}{c}{}
\end{tabular}

Podemos observar que os cruzamentos de 'não' e 'sim' nessa tabela produziram grande porcentagem $(23,10 \%$ para o 'não-não' e 
55,52\% para o 'sim-sim') em relação aos 'híbridos' sim-não (6,21\% e 14,83\%). Ou seja, podemos perceber certa influência, ou, no mínimo, algum tipo de compartilhamento da estratégia - seguido, provavelmente, de seu funcionamento. Novamente, uma pesquisa qualitativa pode tornar esse objeto mais escrutinado.

Novamente, podemos agora abordar a 'farsa' na tabela 9:

Tabela 9: alteração do lattes e omissão

\begin{tabular}{lrrrr} 
& SR & Não & Sim & Total geral \\
\hline \hline Não & $0,34 \%$ & $34,48 \%$ & $3,10 \%$ & $37,93 \%$ \\
Sim & & $44,14 \%$ & $17,93 \%$ & $62,07 \%$ \\
Total geral & $0,34 \%$ & $\begin{array}{c}78,62 \% \\
\text { Fonte: Autoria própria. }\end{array}$ & 21,03\% & $100,00 \%$ \\
& \multicolumn{4}{c}{}
\end{tabular}

Podemos observar que a maioria dos respondentes não altera o seu currículo lattes posteriormente, o que reforça a separação entre academia e mercado $(44,14 \%)$, enquanto uma minoria tem esse receio da consulta online (17,93\%). Podemos perceber que $34,48 \%$ não modifica ambos, e há quem modifique apenas o Lattes $(3,10 \%)$. Ou seja, há uma grande utilidade do Lattes para além do registro extensivo da carreira do pesquisador, ele pode se tornar ele mesmo um CV.

O último cruzamento interessante é a da motivação e da omissão:

Tabela 10: Motivação e omissão

\begin{tabular}{|c|c|c|c|c|c|c|}
\hline & 告 & 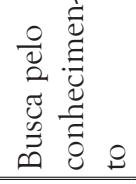 & 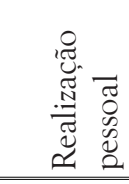 & 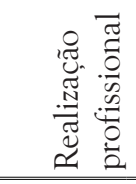 & 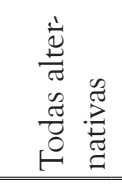 & 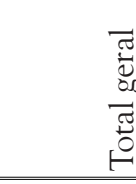 \\
\hline Não & $0,69 \%$ & $9,31 \%$ & $10,69 \%$ & $15,52 \%$ & $1,72 \%$ & $37,93 \%$ \\
\hline Sim & & $12,07 \%$ & $17,59 \%$ & $29,31 \%$ & $3,10 \%$ & $62,07 \%$ \\
\hline Total geral & $0,69 \%$ & $21,38 \%$ & $28,28 \%$ & $44,83 \%$ & $4,83 \%$ & $100,00 \%$ \\
\hline
\end{tabular}

Fonte: Autoria própria. 
Tal qual já havia surgido anteriormente, à realização profissional foi a que mais apareceu na amostra $(29,31 \%)$ dos que responderam que omitiram, seguido da realização pessoal $(17,59 \%)$ e da busca pelo conhecimento (12,07\%). Nesse sentido, podemos perceber que a pós se resguarda de uma esperança de ascenção social, o que não se reflete nos dados - visto que há justamente a omissão dos títulos como uma tendência bastante expressiva.

O último procedimento foi o teste chi quadrado, aplicado nas abas da tabela principal, na tabela 11 :

Tabela 11: teste das variáveis dependentes e independentes

\begin{tabular}{|l|l|l|}
\hline \multicolumn{1}{|c|}{ Cruzamento } & Resultado do Teste de Pearson & \multicolumn{1}{|c|}{$5 \%(\mathrm{P} \leq 0,05)$} \\
\hline Região e omissão & 0,4127261793 & Não-relacionados \\
\hline Idade e omissão & 0,294958142 & Não-relacionados \\
\hline Ocupação e omissão & 0,024184422 & Relacionados \\
\hline Gênero e omissão & 0,1952273469 & Não-relacionados \\
\hline $\begin{array}{l}\text { Com quantos mora e } \\
\text { omissão }\end{array}$ & 0,554353719 & Não-relacionados \\
\hline Escolaridade e omissão & 0,08940178647 & Não-relacionados \\
\hline Área e omissão & 0,2533413689 & Não-relacionados \\
\hline $\begin{array}{l}\text { Conhece alguém e } \\
\text { omissão }\end{array}$ & 0 & Não-relacionados \\
\hline Motivação e omissão & 0,2723308105 & Não-relacionados \\
\hline
\end{tabular}

Fonte: Autoria própria.

Segundo o cálculo, portanto, a hipótese está refutada na medida em que o número de habitantes na dimensão doméstica, quando submetido ao teste, deu como resultado o número 0,554353719. Nesse 
ponto, a casa decimal extra impede a correlação. A única variável que, de fato, é menor que o valor de 0,05 é a da ocupação, cujo resultado foi de 0,024184422. Dentro do universo estudado, portanto, é a ocupação que desempenha a influência decisiva: é ela que determina se vai haver ou não a omissão de títulos.

Por fim, vamos apresentar os dados qualitativos já analisados:

\section{. 'Dois mundos'}

Dimensão pública: foi relatada a percepção da existência de poucos concursos públicos, de modo que há respondentes que afirmam que estão prestando concursos para nível médio; no interior dos programas de pós-graduação, o ambiente acadêmico se mostrou bastante hostil (competição ou abandono), porém sem a recompensa posterior da empregabilidade;

Dimensão privada:

- Educação: universidades privadas gravam aulas e contratam professores com menores titulações, com o objetivo de reduzir seus custos; Aparentemente, onde há mais omissão são nas seleções para professores de nível básico e superior; foi relatado, adicionalmente, que uma nova regra do MEC [a Resolução no 1, de 6 de abril de 2018 do CNE/CES] que diminuiu a necessidade de mestres e doutores e aumentou o número de especialistas em cursos de pós-graduação brasileiros;

Outras áreas:

- Dentro do País: segundo relatos, o Brasil não possui autonomia e replica ciência e tecnologia do exterior, o que já excluiria a necessidade da atuação de um cientista. Houve alguns relatos de que os recrutadores, muitas vezes, aparentam ter medo de contratar alguém mais qualificado; outro dado surpreendente é que apareceram narrativas de que as empresas não-acadêmicas dariam mais importância para um doutorado, especialmente as da área industrial e que lidam com tecnologia; 
- Fora do país: houve quem se mudou para fora do país, após viver de trabalhos informais ('bicos'), desistindo de tentar se estabelecer no país;

\section{. Experiência/Qualificação/Habilidades}

Alguns participantes relataram que a experiência acaba sendo mais importante do que o ensino formal (qualificação formal), o que evidentemente prejudica os mais jovens na obtenção de seu primeiro emprego; outros apontaram para o foco maior em procedimentos (habilidades) do que na produção de conhecimento; outros afirmaram, ao contrário, que o foco das organizações é na rede de contatos e não nas habilidades possíveis, o que demonstra certa variabilidade no mundo do trabalho. Outros relataram que recrutadores justificaram negativas por conta de super qualificação, o que resultou em alguns coachs recomendarem a retirada de títulos do CV (o que funcionou para alguns participantes); Ademais, muitos dos empregos adquiridos pedem pré-requisitos bastante extensos e a remuneração é baixa, pois os empregadores preferem pagar apenas pela habilidade e não pelo título (o que é contrário na iniciativa privada); Alguns relatos apontam para a criação de diferentes versões dos currículos, e que mesmo assim trabalham em áreas diferentes da formação. Foram muitos relatos de desemprego desde a formação;

\section{- Separação academia/mundo prático}

As produções registradas no currículo lattes, aparentemente, são valorizadas apenas no ambiente das universidades; isso evidencia o ponto da separação entre acadêmico e o mundo do trabalho, visto que houve quem reforçou que experiência em ensino médio não devia nem mesmo ser registrada no Lattes; por isso, muitos participantes relataram desejar uma carreira no setor público (que valoriza o diploma com a Retribuição por Titulação), e as empresas aparentemente percebem isso; houve quem relatou que os artigos são inóspitos para quem é de fora da academia, o que ressalta a fronteira. 


\section{. O risco da trajetória}

Foi relatado uma espécie de encruzilhada. Há, por exemplo, quem relatou estar no 'limbo' entre mundo acadêmico e mundo do trabalho: pouca experiência (para a iniciativa privada) e poucas publicações (para certames públicos); Houve afirmações de que, mesmo já trabalhando, houve quem omitisse titulação por medo de ser dispensado na ocupação devido às ocupações da pós-graduação - profissionais da área saúde, por exemplo, relataram precisar pedir por uma escala fixa de trabalho. Portanto, há um risco detectado: para se estar num dos mundos é preciso abdicar do outro. Se alguém quiser seguir carreira acadêmica, precisará abdicar da experiência profissional; se quiser focar no profissional, não conseguirá se dedicar à formação (ou a esconderá). No fim, se esse mesmo não lograr um emprego público, estará despreparado para a vida no setor privado (muitas vezes nem conhecendo suas rotinas) - e, mesmo que se consiga uma ocupação formal na iniciativa privada, a pós não acrescentará significativamente na remuneração. Houve relatos de que a pós impediu que o participante negociasse seu próprio salário e isso lhe trouxe arrependimento de cursá-la.

\section{Análise global dos dados}

Globalmente, podemos perceber que os dados quantitativos apontam para uma situação de dificuldade dos participantes, e os dados qualitativos apontaram para acontecimentos que envolvem mais indivíduos. Não se trata, é claro, de acreditar apenas na palavra dos pós-gradua(n)dos, mas sim construir hipóteses que estimularão investigações posteriores.

Podemos perceber que os dados quantitativos estão apontando para uma prática que atinge os grandes centros e se direciona para os menores. Os dados qualitativos provaram que ela é uma estratégia usada em um deserto de dignidade, e alguns encaram a pós-graduação como a miragem de um oásis. Isso parece ter uma explicação herme- 
nêutica: houve participantes que começaram sua qualificação no período da social-democracia e terminou de estudar depois. Nesse caso, é preciso lidar com a nostalgia da realidade que cambiou ao mesmo tempo em que se precisa adaptar a ela.

Outro traço importante é o abismo percebido entre o mundo onde ocorre a formação e o mundo onde há a atuação. Há uma dificuldade em ingressar em ambos, pois as normas que os guiam são completamente diferentes - o que se ilustra pela separação entre o CV e o Lattes e também pelos pré-requisitos exigidos, que não são intercambiáveis (experiência e publicações). Nesse caso, são dois mundos e uma encruzilhada que implicam em uma aposta - que é aprendida na prática.

Outro ponto parece ser um desconhecimento do papel da pósgradua(n)do. No entanto, essa diferença não parece ser compreendida por quem é de fora do campo acadêmico: nesse sentido, a graduação parece ser melhor compreendida, pois parece estar mais ligada com as habilidades - que parecem ser mais valorizadas do que a formação em si, reforçando a empiria do conceito de menu trabalhista (Lopes 2020).

\section{Considerações finais}

Este artigo tratou da prática de ocultamento de títulos do curriculum vitae por parte de pós-graduandos e pós-graduados brasileiros. A pesquisa foi de caráter quantitativo, buscando as tendências da prática dentro do grupo abordado. Os dados foram tratados a partir da construção de gráficos univariados, bivariados e testes estatísticos de chi quadrado de Pearson. A partir desse estudo, podemos tecer algumas considerações finais.

A primeira reflexão parte do acompanhamento dos resultados em tempo real. As proporções variaram muito, o que indica que houve certa dinâmica na distribuição dos questionários. E, assim, abre-se até uma nova fronteira para o estudo sociológico: o desenvolvimento dos dados fornecendo também dados para a pesquisa. Sabemos que a fí- 
sica, por exemplo, estuda esse tipo de movimento em função do tempo. É claro que, no fim das contas, o que importa ao sociólogo é o consolidado final das informações. No entanto, existem objetos em que a composição desse pool pode ser interessante, especialmente aqueles em que os indivíduos aproximam-se do sociólogo de maneira espontânea.

Os relatos deram a entender um sentimento de nostalgia, especialmente com o momento de forte investimento na educação da social-democracia. Se esse volume de recursos cumpriu sua função ou estava sendo uma medida não sustentável é uma questão que cabe à análise dos dados primários provenientes dos campos da educação e da economia. O certo é que o pós-gradua(n)do parece ter se igualado aos atletas e aos artistas na tentativa de viver de sua especialidade: eles precisam se submeter a outros tipos de trabalho até conseguirem uma chance na sua área, quando ela vem.

Adicionalmente, podemos retirar de uma das matérias que serviram para se extrair o problema social o seguinte trecho: "os três fatores mais importantes que as firmas procuram são comprometimento, flexibilidade e facilidade de relacionamento" (BBC 2017:s/p). Um dos valores procurados pelos empregadores atualmente, portanto, é o do comprometimento, o que fica difícil, de fato, aferir em uma sociedade com pouca coesão social. Nesse caso, o fiel da balança parece ser a experiência de trabalho anterior, que indicaria, no mínimo, uma integração anterior em outro ambiente. Nesse caso, a questão moral, mais do que nunca, se apresenta na sociologia do trabalho e enseja reflexões futuras.

A expansão dos programas de pós-graduação encontrou uma retração do mercado. Isso ocorreu porque os programas não se preocuparam com as demandas de mercado. No entanto, esse investimento massivo permitiu o cultivo de muitos pesquisadores de excelência (possivelmente as turmas cheias tenham auxiliado numa aprendizagem), e que possivelmente não existiriam se existisse apenas a demanda do mercado. Ou seja, não há respostas corretas ou fórmulas prontas, pois 
há interdependência dos fenômenos e imprevisibilidade nos resultados. Assim, o desemprego de muitos dos pós-gradua(n)dos pode ser um efeito colateral incontornável.

\section{Referências:}

AGÊNCIA BRASIL. 2019. Pesquisa revela crescimento de $74 \%$ dos alunos de pós-graduação no país. (https://educacao.uol.com.br/noticias/2019/12/06/ pesquisa-revela-crescimento-de-74-dos-alunos-de-pos-graduacao-no-pais.htm?; acesso em: 10/06/2021).

ALMEIDA, Carlos. 2017. "O ‘Curriculum Vitae’ em Cirurgia”. Revista Portuguesa de Cirurgia, 3(42):51-54.

BARDAGI, M. et al. 2006. "Escolha profissional e inserção no mercado de trabalho: percepções de estudantes formandos”. Psicologia escolar e educacional, 10(1):69-82.

BBC. 2017. Esconder qualificações no currículo: a 'tática' para conseguir emprego que floresce na crise. (https://g1.globo.com/economia/concursos-eemprego/noticia/esconder-qualificacoes-no-curriculo-a-tatica-para-conseguiremprego-que-floresce-na-crise.ghtml; acesso em 31/05/2021).

BRESSER-PEREIRA, Luiz C. 2013. "Empresários, o governo do PT e o desenvolvimentismo". Revista de sociologia e politica, 21(47):21-29.

JUNGES, Cíntia. 2017. "Qualificação demais espanta oportunidades na crise? Tem gente dizendo que sim”. Gazeta do Povo. (www.gazetadopovo.com.br/ economia/pos-e-carreira/qualificacao-demais-espanta-oportunidades-nacrise-tem-gente-dizendo-que-sim-6ubt4uuumbht95n 16fholb901/; acesso em 08/06/2021).

GASPARINI, Claudia. 2014. "10 erros que fazem seu currículo ir para o lixo”. Exame. (https://exame.com/carreira/10-erros-que-fazem-o-seucurriculo-ir-direto-para-o-lixo/\#: : :text=Para\%20um\%20 candidato $\% 20$ em\%20in\%C3\%ADcio,de\%20informa\%C3\%A7\%C3\%B5es\%20importantes\%E2\%80\%9D\%2C\%20explica; acesso em 20/07/2020).

GIL, Antonio C. 2019. Métodos e técnicas de pesquisa social. São Paulo: Atlas SA.

GOMES, H., DE OLIVEIRA, S. \& ANDRADE, M. 2019. "Desemprego, juventude e crise estrutural do capital: o precariado na cena contemporânea". INTERthesis: Revista Internacional Interdisciplinar, 16(3):18-38.

LOPES, R., COElHO, G. \& FRANZ, A. 2020. "A Covid-19, o Pós-Graduando Stricto Sensu e o Auxílio Emergencial: dispor ou não dispor?". Revista Observatório, 6(2):a14pt-a14pt.

. 2020. “O 'Menu' Trabalhista: a emergência do analista técnico e a fragmentação do bacharel”. Orbis Latina, 10(3):13-36. 
RIGHETTI, S. \& GAMBA, E. 2021. "Na pós-graduação, mulheres são maioria entre estudantes mas minoria entre docentes". Folha de São Paulo. (www1. folha.uol.com.br/educacao/2021/03/na-pos-graduacao-mulheres-sao-maioriaentre-estudantes-mas-minoria-entre-docentes.shtml; acesso em 10/06/2021).

SACRISTÁN, José G. 2013. "O que significa o currículo". In SACRISTÁN, J. G. (ed.): Saberes e incertezas sobre o curriculo, pp. 16-35. Porto Alegre: Pens.

SILVA, T. \& BARDAGI, M. 2015. "O aluno de pós-graduação stricto sensu no Brasil: revisão da literatura dos últimos 20 anos". Revista Brasileira de PósGraduação, 12(29):683-714.

SILVA JÚNIOR, J., FERREIRA, L. \& KATO, F. 2013. “Trabalho do professor pesquisador diante da expansão da pós-graduação no Brasil pós-LDB”. Revista Brasileira de Educação, 18(53):435-456.

ZOTESSO, Marina. 2021. Sofrimento psicológico em pós-graduandos: aspectos emocionais e comportamentais. Tese de Doutorado. Bauru: Universidade Estadual Paulista.

\begin{abstract}
This article seeks to study the labor scenario for Brazilian postgraduates and postgraduates based on the recurrence of the practice of omitting academic degrees in the curriculum vitae of this public. This research is quantitative in nature, and its data collection occurred from the availability of the questionnaire in virtual communities of graduate students and undergraduates on the facebook social network. The idea was to reach the highest number of responses within the national territory, seeking representation from all regions, and in this, 302 responses were obtained. The survey indicated that the practice is very recurrent and that it is more related to the respondent's current occupation. It was also possible to analyze the answers to an open question in the questionnaire, 'Two worlds', Experience/Qualification/Skills, Separation of academia/world and the Risk of trajectory, which pointed to a hostile environment in both the public and private dimensions, which puts participants at a crossroads.
\end{abstract}

Keywords: Omission of title, Graduate students, Postgraduates, Unemployment.

Recebido em dezembro de 2020.

Aprovado em junho de 2021. 